

\author{
A fotografia como téenica e objeto \\ de estudo na pesquisa qualitativa
}

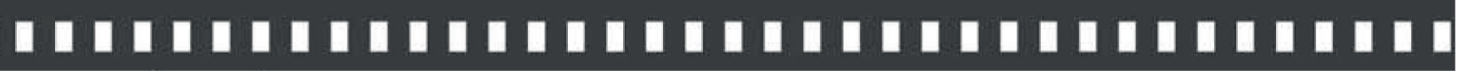

\author{
Sadraque 0liveira Rios \\ Jean Mario Araujo Costa \\ Vera Lucia Peixoto Santos Mendes \\ Artigo recebido em: 14/07/2015 \\ Artigo aprovado em: 14/07/2016
}




\title{
A fotografia como técnica e objeto de estudo na pesquisa qualitativa
}

\author{
The photography as technique and object \\ of study in qualitative research
}

Sadraque Oliveira Rios*, Jean Mario Araujo Costa*** e Vera Lucia Peixoto Santos Mendes***

\begin{abstract}
Resumo: O presente trabalho tem o objetivo de discutir a fotografia na pesquisa qualitativa, a partir de levantamento de bibliografia. Situa-se a fotografia no contexto da evolução tecnológica do século XIX, apresentando seus atributos como objeto e técnica de pesquisa, as vantagens e limitações de seu uso e as diretrizes de interpretação crítica. Concluindo, apresenta-se a análise de dois trabalhos cientificos que fazem exemplar uso da fotografia na pesquisa qualitativa.
\end{abstract}

Palavras-chave: Fotografia. Pesquisa. Estética Organizacional. Fotografia dos Espíritos.

\begin{abstract}
This paper aims to discuss photography in qualitative research on literature review. Photograph is located in the context of technological developments in the nineteenth century, with its attributes as object and technical research, the advantages and limitations of its use and critical interpretation guidelines. In conclusion, we present the analysis of two scientific papers that make exemplary use of photography in qualitative research.
\end{abstract}

Keywords: Photography. Research. Organizational aesthetics. Photography of the Spirits.

* Doutorando em Administração Pública pela Universidade Federal da Bahia, especialista em Direito Público pela Universidade Anhanguera e Bacharel em Direito pela Universidade Estadual de Feira de Santana. É Juiz de Direito do Tribunal de Justiça do Estado da Bahia.

** Doutor e mestre em educação pela Universidade Federal da Bahia, especialista em Política do Planejamento Pedagógico e Licenciado em Pedagogia pela Universidade do Estado da Bahia. Professor do Programa Escola de Gestores, 


\section{Introdução}

A produção do conhecimento científico na contemporaneidade possui marca notória de pluralidade quanto às técnicas, dado o avanço tecnológico que permite ampla variação dos meios com que o homem descobre, interage e compreende os objetos do saber.

Bem verdade, de acordo com Santos (2000, p. 65), “desde o século XIX, o historiador francês Fustel de Coulanges afirmava que onde havia marcas humanas havia história". Mais tarde, "Marc Bloch e Lucien Fevre tematizavam a importância do caráter generalizador dos testemunhos, abrindo as portas da história para os novos textos, tais como pintura, cinema e fotografia" (SANTOS, 2000, p. 65).

A esse respeito, muitos escritores têm voltado suas pesquisas para o visual como centro da produção de cultura da vida social nas sociedades ocidentais contemporâneas, com destaque para as ciências da Antropologia e da Sociologia.

Assim, vem sendo desenvolvida uma "sociologia visual" centrada em recursos como a fotografia e o filme. Trata-se de técnicas visuais correspondentes a práticas de pesquisa científica em vários modos, incluindo pintura, fotografia, vídeo, filme e páginas de internet.

Neste breve artigo, será discutido o uso da fotografia em pesquisa qualitativa. A primeira parte abordará os atributos da fotografia como técnica, as vantagens e limitações de seu uso e as diretrizes de interpretação crítica da fotografia no campo da pesquisa. Na segunda parte, dois trabalhos científicos - um artigo da Organizational Studies e uma tese de doutorado da Universidade

Curso de Especialização (lato sensu) em Coordenação Pedagógica da Universidade Federal da Bahia.

*** Doutora e mestre em Administração pela Universidade Federal da Bahia. Professora e Pesquisadora do Núcleo de Pós-Graduação em Administração da Universidade Federal da Bahia, onde coordena o Grupo de Pesquisa Observa Políticas. 
de São Paulo - que fazem exemplar uso da técnica fotográfica serão analisados sob esse ângulo. Por fim, serão tecidas considerações finais.

\section{Os estudos sobre o uso da fotografia}

\section{na pesquisa qualitativa}

Oficialmente registrada como uma invenção de Daguerre, em 1839, a fotografia representa o advento do primeiro meio de produção automática da imagem, que assume gradativamente o papel de instrumento de mediação, registro e arquivamento (ANDRADE, 2008).

Do ponto de vista conceitual, Monteiro (2006, p. 12) assevera:

a fotografia é um recorte do real. Primeiramente, um corte no fluxo do tempo real, o congelamento de um instante separado da sucessão dos acontecimentos. Em segundo lugar, ela é um fragmento escolhido pelo fotógrafo pela seleção do tema, dos sujeitos, do entorno, do enquadramento, do sentido, da luminosidade, da forma etc. Em terceiro lugar, transforma o tridimensional em bidimensional, reduz a gama das cores e simula a profundidade do campo de visão.

A fotografia guarda um elo físico com o seu referente. Ela seria uma marca deixada pelo "fluxo fotônico emitido ou refletido por um corpo físico (pessoa ou objeto) sobre uma superfície sensível (filme, papel etc.)", como afirma Jean-Marie Schaeffer (apud MONTEIRO, 2006, p. 12).

Por outro lado, as imagens são ambíguas e passíveis de múltiplas interpretações. Por isso, é necessário um aprendizado desse código e uma cuidadosa discussão teórico-metodológica. 
Atendo-se à ligação das imagens com a pesquisa e com as incursões científicas, infere-se que ora a fotografia se apresenta como fonte de dados em si mesma, ora como objeto de pesquisa, mas que também pode ser instrumento e resultado (SANTOS, 2000), ou ainda, como defende Warren (2009), uma combinação dessas categorias.

A ideia do "ver para crer" é, para Warren (2009), provavelmente uma importante razão a explicar como a fotografia tem sido tradicionalmente utilizada para documentar eventos e processos, nas ciências sociais.

As fotografias têm alta qualidade icônica, o que pode auxiliar a ativar lembranças das pessoas ou estimulá-las a elaborarem enunciados sobre situações e processos complexos (FLICK, 2009).

Outrossim, sobreleva-se o valor epistêmico da fotografia enquanto imagem, ou seja, as informações que a foto traz sobre o mundo (SANTOS, 2000). As fotografias são gravações detalhadas de fatos, além de que proporcionam uma apresentação mais abrangente e holística de estilos e condições de vida (MEAD apud FLICK, 2009).

Outro aspecto positivo da técnica é o registro em imagens dos ícones da memória. As fotografias, em geral, "sobrevivem após o desaparecimento físico do referente que as originou: são os elos documentais e afetivos que perpetuam a memória" (KOSSOY apud SOARES; SUZUKI, 2009, p. 9).

Fotografias podem produzir dados que ampliam nossa compreensão sobre processos sociológicos, vez que "gravam detalhes que podem instigar os expectadores a refletirem sobre realidades culturais mais amplas" (HARPER, 2000, p. 727, tradução nossa).

Stafford (apud ROSE, 2001) afirma que, no início do século XVIII, a construção do pensamento científico sobre o mundo se tornou cada vez mais baseada em imagens do que em textos escritos, especialmente em virtude de constatar que, nas sociedades ocidentais, o avanço da tecnologia tem promovido a aproximação 
entre o "ver" e o "conhecer" (saber multissensorial).

A fotografia pressupõe a existência de duas mensagens: uma sem código (analogia fotográfica) e outra com código (arte, tratamento, escrita ou retórica da fotografia). Estas demarcam uma colisão de uma mensagem conotativa e outra denotativa - termos utilizados por Barthes (apud SANTOS, 2000), para qualificar o "paradoxo fotográfico" entre o plano da forma de conteúdo e o plano da forma de expressão.

Ainda conforme Barthes (apud SANTOS, 2000), a fotografia possui dois elementos estruturais: o studium e o punctum. O primeiro corresponde ao campo codificado intencionalmente pelo fotógrafo ("foto do fotógrafo", "interesse geral despertado pela foto", "afeto médio"). Por sua vez, o punctum é o detalhe que chama a atenção daquele que olha a foto; é o objeto parcial de desejo, não intencional e não codificado ("foto do espectador").

Por todas essas considerações peculiares, o uso da fotografia nas ciências sociais encontrou fértil espaço diante da crise de paradigmas a partir da década 1980, em que as metodologias e as técnicas dominantes no campo científico das ciências sociais foram redimensionadas com a constatação de seus limites interpretativos.

Em obra de relevo, Mello (1999) assevera que um dos aspectos dessa crise foi o reconhecimento do hiato entre as ciências sociais e a discussão sobre as formas de representação da visualidade contemporânea e dos avanços das novas tecnologias de comunicação e produção de suportes imagéticos.

Então, fundam-se novas bases teórico-epistemológicas nas ciências sociais mediante incorporação de novos temas, objetos e estratégias nesse campo científico. Essa importância atribuída a "ler", produzir e interpretar criticamente a linguagem visual permitiu transformar a perspectiva imagética em mais do que simples "realidade objetiva", porém instrumento do cientista social para entender os significados engendrados pelas imagens, suas formas de produção e mediação de sentido. Com essa proposta, destacam-se, além dos já citados, os trabalhos de Sontag (1973), 
Mead (1979), Collier Jr. e Collier (1986), Ferrarotti (1993) e Sweetman (2009) e, no Brasil, Godoy (1995), Leite e FeldmanBianco (1998), Koury (1999), Martins (2008), De Paula e Marques (2010), Medina Filho (2013) e Menezes (2013).

Essa nova interface contribuiu para questionar a postura neutra do "observador participante", trazendo para as ciências sociais a relevância de se pensar o resultado da interação entre pesquisadores, pesquisados, contexto e produto. De fato, Kossoy (apud MONTEIRO, 2006) aponta para a necessidade de pensar a tríade sujeito (fotógrafo), técnica (equipamento) e assunto (história do tema a ser abordado). Assim justifica o autor:

primeiramente, o historiador deveria procurar informações sobre a atuação profissional do fotógrafo: se possuía um ateliê, qual era a sua clientela, se trabalhava por encomenda para uma empresa ou administração, a classe social a que pertencia, os seus gostos e os preços cobrados. Dever-seia levar em conta ainda os filtros culturais e ideológicos de classe do fotógrafo e de sua época. Outra variável diria respeito aos equipamentos e às técnicas empregadas: tipo de câmara, tipo de negativo, lentes, forma de revelação, formato das fotografias etc. Finalmente, o assunto deve ser colocado no seu tempo e gênero específicos: retrato, vistas urbanas, cartão-postal, álbum de família, último retrato ou fotorreportagem (MONTEIRO, 2006, p. 13).

A importância de pensar a função da imagem, o porquê de sua produção e para que tem servido a veiculação das imagens é fundamental quando utilizada como fonte para estudo, como objeto de pesquisa ou de conhecimento, de modo a contextualizá-la histórica e culturalmente.

Mauad (apud MONTEIRO, 2006) estabelece para a análise das imagens fotográficas cinco categorias espaciais que abrangem tanto o plano do conteúdo (significante visual) quanto o da expressão (significado propriamente), servindo como método de 
interpretação:

a) Espaço fotográfico: recorte espacial processado pela fotografia (tamanho, formato, enquadramento, nitidez e o produtor);

b) Espaço geográfico: espaço físico representado na fotografia (local retratado, ano e atributos da paisagem);

c) Espaço do objeto: compreende os objetos fotografados;

d) Espaço de figuração: compreende as pessoas retratadas, a natureza deste espaço, a hierarquia das figuras e outros atributos;

e) Espaço de vivência: tema da foto.

Por seu turno, para Rose (2001), o significado de uma imagem ou conjunto de imagens é feito em três locais: o local de produção, a imagem em si mesma e seu público.

O local da produção é relevante, pois toda representação visual é produzida de um modo específico (e não de outro, dada a existência de um contexto de variedade de meios); logo, as circunstâncias de sua produção contribuem indubitavelmente em direção ao efeito que ela possua.

No que se refere à imagem, é sabido que toda representação visual (aqui também compreendida a fotografia) possui componentes formais. Esses elementos tanto decorrem das tecnologias empregadas para fazer, reproduzir ou mostrar a imagem, como também dependem das práticas sociais associadas à compreensão prévia do objeto fotografado.

Além disso, o significado da imagem está associado ao seu público, vez que este é o destinatário da mensagem e, nesse percurso de comunicação, a interpretação final depende do público que a recepcionará.

Do ponto de vista da execução da técnica da fotografia, Barthes (apud FLICK, 2009, p. 220) distingue quatro tipos de relações entre o pesquisador e os pesquisados:

o pesquisador pode mostrar fotos (como demonstrador) 
para pessoas em estudo (como espectadores), questionando-os quanto ao material (tipo I). O operador (que tira a fotografia) pode utilizar o indivíduo pesquisado como um modelo (tipo II). Os pesquisadores (como espectadores) podem pedir que o sujeito mostre fotografias sobre um determinado tópico ou período (como demonstrador) (tipo III). Por fim, o pesquisador (como espectador) pode observar os sujeitos (como operadores) enquanto tiram uma fotografia e conduzem uma análise sobre o material escolhido para ser fotografado (tipo IV).

Neste prisma, visualizadas diversas vantagens quanto ao uso da fotografia, então, quais os problemas na aplicação desta técnica?

Um dos problemas é a influência do meio, isto é, o posicionamento intencional dos sujeitos a serem fotografados, a chamada "pose", que, geralmente, acarreta a perda da expressividade do momento.

Outro problema é a possibilidade de a fotografia ser influenciada ou manipulada na elaboração ou na apresentação (ex.: montagem e retoques). Neste particular, destacam-se a questão do enquadramento (o que está na fotografia, o que está sendo focalizado, o que é deixado de fora?) e o estilo estético pessoal do fotógrafo ("controle sobre a imagem final": a escolha da lente, da revelação e do papel, das lentes e da câmera, do momento e das relações com os sujeitos - todos esses aspectos sob controle direto do fotógrafo). Consequentemente, pode se restringir a realização e a confiabilidade das fotografias como dados das ciências sociais (BECKER apud FLICK, 2009).

Além do mais, de acordo com Rose (2001), a "aparente veracidade" da fotografia tem menos relação com as habilidades tecnológicas da câmera e do filme e mais pertinência sobre como fotografias são compreendidas.

Neste contexto, Rose (2001) afirma que imagens, dentre elas a fotografia, nunca são inocentes. As imagens não são "janelas 
transparentes para o mundo" (p. 6, tradução nossa). Elas interpretam o mundo, mostrando-o em diversas formas particulares.

Em geral e como se observa acima, diversas questões metodológicas têm sido discutidas, com destaque para Denzin (apud FLICK, 2009, p. 221):

Suposições teóricas que determinam o que é fotografado e quando, que aspecto é selecionado para análise a partir da fotografia etc. deixam sua marca na utilização das fotografias como dados ou para a documentação de relações; as câmeras são incorruptíveis em termos de sua percepção e documentação do mundo, no entanto também transformam o mundo conforme o modo como o apresentam; as fotografias contam a verdade, porém até que ponto estão também marcadas pela interpretação e pela atribuição daqueles que tiram e a observam?; as fotos revelam uma abordagem ao mundo simbólico dos sujeitos e suas opiniões.

Logo, Becker (apud HARPER, 2000, p. 729), de forma inovadora e relevante, defende um "pensar teórico" quando se fotografa. Harper explica:

para Becker, toda fotografia é feita a partir de uma perspectiva teórica, mas um pouco dessa teoria é sociológica. Nossas visões normais do mundo (que Becker chama de teoria "leiga") nos revelam onde posicionar a câmera e como usá-la (falando tecnicamente) para fazer imagens. Assim, quando nós fotografamos, nós recriamos nossas não examinadas, tomadas como certas percepções. Nós estaremos interpretando sociologicamente pontos em nossa teoria não examinada e nossas fotografias serão nossas conclusões (HARPER, 2000, p. 729, tradução nossa). 
Cotejadas as vantagens e as dificuldades da técnica, cumpre examinar as restrições no uso da mesma.

As três principais propriedades da fotografia são os "detalhes, a força comunicativa e a iconografia" (WARREN, 2009, p. 572, tradução nossa). Contudo, essas marcas distintivas também se controvertem no ambiente organizacional. Para Warren (2009), a "política do lucro" restringe o que pode ser fotografado e por quem. A sensibilidade comercial e a privacidade do cliente podem limitar o que os pesquisadores estão permitidos de fotografar. Além disso, existem as discussões sobre direitos autorais.

Portanto, se existem sérios complicadores no uso da fotografia a comprometerem a validade científica de seus resultados como técnica de pesquisa, como desenvolver uma metodologia crítica de compreensão do visual da fotografia?

Para Rose (2001), uma abordagem interpretativa crítica necessariamente envolve:

a) Levar a imagem a sério, especialmente pela sua historicidade, contextualização e, ao mesmo tempo, autonomia de efeitos em relação ao objeto-referente;

b) Pensar sobre as condições sociais e efeitos dos objetos visuais;

c) Considerar a forma pela qual o pesquisador está analisando a imagem, compreendendo que nenhum olhar sobre a fotografia é inocente. Dessa forma, é necessário refletir sobre o viés crítico do próprio pesquisador.

Estabelecido um panorama teórico acerca da técnica da fotografia, com relevo às inovadoras e primorosas discussões de Becker, Harper (2000), Santos (2000), Rose (2001), Monteiro (2006), Flick (2009) e Warren (2009), serão retratadas adiante, no que se refere ao uso da fotografia, duas pesquisas qualitativas na área: o artigo publicado na revista Organization Studies, intitulado Empirical Challenges in Organizational Aesthetics Research: Towards a Sensual Methodology, cuja autora é Samantha Warren (2008); e a tese de doutorado intitulada $\mathrm{O}$ gabinê fluidificado e a 
fotografia dos espíritos no Brasil: a representação do invisível no território da arte em diálogo com a figuração de fantasmas, aparições luminosas e fenômenos paranormais, elaborada por Mário Celso Ramiro de Andrade, perante a Universidade de São Paulo (2008).

\section{Experiências qualificadas no emprego da fotografia}

As discussões lançadas nos tópicos anteriores centraramse na fotografia e nos seus atributos no contexto da pesquisa qualitativa, tanto no prisma de técnica de pesquisa, quanto como objeto, em si, de investigação. Neste tópico, são apresentados dois trabalhos científicos em pesquisa qualitativa, os quais, no âmbito do uso da fotografia, permitem uma compreensão didática de seus figurinos e de alguns conceitos expostos anteriormente.

Assim,tem-seoartigoEmpiricalChallengesinOrganizational Aesthetics Research: Towards a Sensual Methodology, de Samantha Warren, em que a fotografia é simultaneamente técnica e objeto de pesquisa. Além disso, apresenta-se a tese $\mathrm{O}$ gabinê fluidificado e a fotografia dos espíritos no Brasil: a representação do invisível no território da arte em diálogo com a figuração de fantasmas, aparições luminosas e fenômenos paranormais, escrita por Mário Celso Ramiro de Andrade, em que a fotografia é predominantemente objeto de pesquisa científica.

\section{Empirical Challenges in Organizational Aesthetics Research: Towards a Sensual Methodology}

$\mathrm{O}$ artigo em questão foi publicado originariamente em 8 de fevereiro de 2008 na revista Organization Studies, propondo-se a contribuir com os estudos metodológicos, de forma primorosa e inovadora, sobre como fazer pesquisa estética. Para tanto, a autora desenvolve uma revisão crítica dos métodos usados por outros escritores em estética organizacional e apresenta um sumário de 
suas próprias pesquisas.

No referencial teórico, Warren (2008) cita Bourdieu para informar que o campo da estética é composto por dois elementos distintos e conceitualmente amplos: o julgamento e a experiência. Embora achados estéticos sejam subjetivamente experimentados e individualmente encorpados, a interpretação dos mesmos é socialmente moldada. Tal prisma complementa o argumento de Rose (2001) e Kossoy (apud MONTEIRO, 2006), acima expostos, a respeito da tríade imagem-visão-compreensão.

A autora apresenta uma vasta série de pesquisas no segmento da estética e da fotografia a fim de apurar o crescente interesse das ciências sociais pelas mesmas. Entretanto, para Warren (2008), as obras citadas permanecem estranhamente silenciosas sobre a complexidade das metodologias empregadas.

Neste ângulo de elucidação metodológica, Warren (2008) traz seu estudo de caso acerca da "estetização no Departamento X". Trata-se de uma pesquisa desenvolvida para explorar as perspectivas dos empregados em um programa de estetização do local de trabalho em um departamento de web-design (Departamento X) de uma empresa multinacional de tecnologia da informação, sediada na parte rural do sul da Inglaterra.

Após as explicações acerca do objeto de estudo e da finalidade do trabalho (tornar o Departamento X um local mais agradável e divertido para se laborar), Warren (2008) detalha o emprego da técnica da fotografia: cada funcionário tirou um conjunto de fotos em uma máquina digital, objetivando representar como eles se sentiam no ambiente de trabalho. Essas imagens foram a base para a realização de uma entrevista semiestruturada entre o funcionário e a pesquisadora.

Assim, três principais técnicas foram utilizadas para a produção de dados: entrevistas biográficas semiestruturadas, etnografia estética e respondent led fotografia (técnica de fotografia em que os participantes são convidados a analisar imagens por eles mesmos retratadas; também é chamada por photo-elicitation, auto- 
driving, photo-novella e photo-interviewing) (WARREN, 2008).

Notadamente em matéria de estética e da pesquisa desenvolvida, a fotografia é técnica bastante apropriada por várias razões apontadas por Warren (2008):

a) Representam uma janela para a compreensão estética do participante;

b) Evocam e recriam experiências estéticas durante as entrevistas;

c) Constituem lugares adequados para explorar a natural construção social dos julgamentos estéticos dos participantes.

Um dos pontos salutares da pesquisa de Warren (2008) consistiu no fato de que os participantes puderam fotografar livremente, destacando de imediato o que era esteticamente importante para eles no ambiente de trabalho; assim, puderam explorar, na prática, as cinco categorias espaciais de Mauad (apud MONTEIRO, 2006) declinadas anteriormente.

Destarte, conscientemente ou não, o que foi escolhido (ou deixado de fora) na fotografia, o ângulo, a escolha do assunto, a composição e a orientação da câmera revelam mais sobre a cultura do participante-fotógrafo do que sobre a cultura do objeto retratado. Isto é, o que a fotografia gera além de si mesma é representativo e corrobora a discussão do tópico anterior sobre a fotografia como um ato social e simbólico (DENZIN apud FLICK, 2009).

Ademais, Warren (2008) apresenta um relevante achado durante as entrevistas guiadas pelas imagens retratadas: a maneira como as fotografias foram interpretadas durante a entrevista foi diferente da motivação original do fotógrafo ao tomá-las, bem como diversa do posterior entendimento individual do espectador delas. Belova (apud WARREN, 2008, p. 573, tradução nossa) afirma se tratar do "evento do ver", em que o "significado é criado em movimento e o diálogo entre imagem, autor, espectador e circunstância da percepção e/ou discurso instiga um efeito-surpresa na obtenção de dados interpretativos". Esse percurso criativo revela que as quatro sobreditas relações entre o pesquisador e os 
pesquisados, examinadas por Barthes (apud FLICK, 2009), não são perfis estanques, havendo, não raro, circunstâncias em que a pesquisa fotográfica desvela os sujeitos participantes ("espectadores" e demonstradores) na composição e na interpretação de sentidos do objeto da pesquisa.

Logo, a relevância da photo-interviews reside na combinação entre língua e imagem. Este é o mérito da pesquisa de Warren (2008) e do artigo em exame, ao representar o avanço das possibilidades sensoriais em pesquisa qualitativa e ao reforçar o "pensar teórico" defendido por Becker (apud HARPER, 2000).

O gabinê fluidificado e a fotografia dos espíritos no Brasil: a representação do invisível no território da arte em diálogo com a figuração de fantasmas, aparições luminosas e fenômenos paranormais

A tese em comento foi apresentada ao Departamento de Artes Plásticas da Escola de Comunicação e Artes da Universidade de São Paulo, em 2008.

A obra procurou atuar em duas frentes de trabalho: rastrear o surgimento e identificar a produção da chamada Fotografia dos Espíritos no Brasil; e uma leitura da produção artística do autor em diálogo com vários pressupostos da Fotografia dos Espíritos.

Diferentemente do cunho metodológico crítico sobre o uso da fotografia para as ciências sociais apresentado no trabalho de Warren (2008), a coetânea tese de Andrade (2008) limita-se a examinar a fotografia como objeto de pesquisa científica sem depurar com clareza o uso problemático, restritivo do objeto estudado.

Assim, no contexto histórico, a Fotografia dos Espíritos no Brasil é definida pelo autor como modalidade fotográfica consistente em um acervo de imagens com características próprias, encontradas a partir do início do século XX no país, "as quais registram as supostas manifestações espirituais e paranormais 
ocorridas no Brasil ao longo de quase um século" (ANDRADE, 2008, p. 6). Trata-se de trabalho pioneiro, abordando a fotografia de modo inovador, vez que dá início a um levantamento de imagens ainda dispersas e pouco analisadas pela história de nossa vida cultural e científica.

$\mathrm{O}$ autor enfoca o surgimento da mesma classe de fotografia nos Estados Unidos e na Europa, ao longo do século XX, em torno das chamadas "materializações espirituais". Entretanto, no Brasil há uma dedicação maior no que toca aos registros dessas aparições, considerada a tradição cultural e o "estilo sacral de compreender a realidade" (CAMARGO apud ANDRADE, 2008, p. 17), inclusive pela força crescente que o Espiritualismo moderno vem alcançando em nosso país.

$\mathrm{O}$ autor, em um primeiro momento, examina diversas imagens coletadas a partir de revistas, livros e catálogos nacionais e estrangeiros, produzidos e publicados ao longo de quase um século, mapeando-as de modo abrangente. Não se tratou de consulta aos registros fotográficos originais, face à dificuldade de localização e acesso. Destaca ainda que, a princípio, essa modalidade de fotografia se desenvolveu em um contexto da religião espírita e da parapsicologia no Brasil, mas atualmente se encontra bastante ligada ao catolicismo em virtude das diversas "aparições marianas" (2008, p. 153).

As principais fontes de estudo do autor foram:

a) O Livro dos Médiuns, publicado em 1861: é um guia que contém ensinamentos sobre a teoria de todos os gêneros de manifestações e os meios de comunicação com o mundo invisível;

b) As fotografias produzidas pelo médium pioneiro fotógrafo Willian Mumler;

c) $\mathrm{O}$ autorretrato de Willian Mumler: considerado como o marco de surgimento da fotografia dos espíritos;

d) As fotografias de Edouard Buguet, Militão de Azevedo, Etore Bosio, Carlos Mirabelli e Peixotinho;

e) O livro de Nogueira de Faria, em que consta a 
primeira fotografia "espírita" publicada no Brasil;

f) Fotografias de espíritos em revistas ilustradas da década de 60 (revista "Fatos e Fotos"; revista "O Cruzeiro"), sendo que, em uma delas, houve uma matéria com meticuloso acompanhamento por médicos e cientistas experts no fenômeno;

g) $\mathrm{O}$ acervo fotográfico dos fenômenos provocados por Thomas Green Morton;

h) Tipologia de fotógrafos clássicos entre 1861 e 1902;

i) Fotografias milagrosas da atualidade.

A partir do estudo realizado, o autor marca a evolução do objeto de estudo: de tênues aparições representadas por delicados contornos ao lado dos retratados a retratos de pessoas encarnadas junto às quais apareciam, mais ou menos nítidos, seres desencarnados (2008, p. 36). Além disso, são abordadas as fotografias de "tratamentos" ou "operações espirituais" (operações cirúrgicas realizadas por médiuns).

Sistematicamente, Lombroso (apud ANDRADE, 2008, p. 119) classifica a existência de seis categorias de fotografias dos espíritos:

a) Retratos de entidades espíritas invisíveis nas condições normais;

b) Flores, escritos, coroas, luzes, imagens estranhas ao pensamento do médium e ao do fotógrafo;

c) Seres que parecem reprodução de estátuas, pinturas ou desenhos;

d) Imagens de formas materializadas, visíveis a todos os assistentes;

e) Reprodução do corpo astral ou duplo de pessoas vivas;

f) Provas (cópias fotográficas) onde a revelação nada fez aparecer, mas onde o médium e os clarividentes distinguem uma imagem que é constante e absolutamente independente da personalidade do observador. 
Desta forma, o objeto de estudo de Andrade (2008) redimensiona a compreensão dos mencionados espaços do objeto e de figuração teorizados por Mauad (apud MONTEIRO, 2006), sendo o ponto de destaque da obra, a fim de buscar incluir elementos que escapam do visível ou, mais precisamente, do espaço natural do visível.

Por certo, o autor não deixa de abordar que a fotografia dos espíritos é uma seara extremamente "pantanosa e propícia às fraudes" (2008, p. 28). Tanto que diversas reportagens colacionadas ao estudo apresentam farsas constatadas por estudiosos. Quanto a isto, apropriado recordar quando Becker (apud FLICK, 2009) afirma a existência de riscos à confiabilidade da fotografia como dado para as ciências sociais.

Com efeito, as imagens são ambíguas e passíveis de múltiplas interpretações. Por isso, é necessário um aprendizado desse código e uma cuidadosa discussão teórico-metodológica, conforme ensina Denzin (apud FLICK, 2009). No entanto, tal desiderato não é suficientemente cumprido por Andrade (2008) da mesma forma que Warren (2008), certamente pela incipiência do objeto para o campo da discussão científica, em pesquisa qualitativa, já que é tradicional apenas ao universo da religião.

Nada obstante, o autor percorre o caminho teórico em defesa da fotografia como protocolo científico, para alçá-la, no registro de fenômenos paranormais, a uma "prova objetiva da existência da vida após a morte, ao revelar um campo de fenômenos invisíveis e muitas vezes impenetráveis aos sentidos humanos" (2008, p. 29). O autor, inclusive, caracteriza a câmera fotográfica como médium.

Como aparelho fruto da ciência e ferramenta de trabalho científico, Andrade (2008) assevera que a câmera fotográfica foi vista, desde o seu surgimento, como o meio por excelência para refletir fielmente a imagem da realidade, tal qual na superfície de um espelho eterno. Não sendo induzidos a alucinações visuais, a lente e o filme, colocado no interior da câmera escura, estariam aptos a captar as manifestações espirituais e traduzi-las objetivamente 
como é feito com a luz visível. Para demonstrar o controle científico empregado nas sessões de experimentação era comum o registro dos próprios equipamentos utilizados na documentação das "experiências mediúnicas".

Ainda em busca da cientificidade (ora não questionada), a descoberta dos raios X, por Wilhelm Conrad Rontgen, em 1985, confirma, para Andrade (2008), a possibilidade da fotografia, no campo da ciência, romper com as barreiras do registro feito apenas com a luz visível. Completa o autor: "com o surgimento dos 'espíritos' nos retratos fotográficos, as câmeras começaram a popularizar aquilo que antes apenas os médiuns videntes eram capazes de visualizar" (p. 31).

Enfim, o conjunto de obras particulares apresentado por Andrade (2008) e a análise da câmera fotográfica como elemento mediúnico foram abordados pelo autor para tentar evidenciar: a continuidade da vida consciente e individualizada após a morte; que grande parte dos fenômenos atribuídos "aos espíritos" seria produto da capacidade humana, observada em indivíduos dotados; $\mathrm{e}$ provar as "manifestações da Virgem, de Jesus, e de alguns milagres ocorridos entre nós" (p. 153).

Do ponto de vista da pesquisa qualitativa, diferentemente do artigo de Warren (2008), que usa a fotografia como técnica e objeto de pesquisa, o trabalho de Andrade (2008) explora a fotografia somente na esfera de objeto de estudo. Por isso, metodologicamente, Warren (2008) apresenta argumentos mais notórios do "pensar teórico" sobre o uso da fotografia, em sintonia com as diretrizes de interpretação crítica apontadas por Rose (2001). Entretanto, ambos os autores são representativos da crescente possibilidade que a fotografia detém no campo de pesquisa qualitativa em ciências sociais. 


\section{Considerações finais}

A fotografia é um recorte da realidade, um corte que promove o congelamento do fluxo do tempo na imagem e, também, um recorte espacial da realidade, através do ângulo, do enquadramento e dos efeitos escolhidos para tratar do tema fotografado.

Neste cenário, o pesquisador precisa colocar a imagem fotográfica em seu tempo e pensá-la em relação à cultura visual (sistemas de comunicação), ao visível que diz respeito à esfera do poder, à ditadura do olho e à visão relacionada aos instrumentos e às técnicas de observação e aos papéis do observador (MENEZES apud MONTEIRO, 2006). Igualmente, Jenks (apud ROSE, 2001, p. 7, tradução nossa) defende que "olhar, ver e conhecer têm se tornado perigosamente entrelaçados, de modo que o mundo moderno é muito mais um fenômeno do "ver"'. Contudo, imagens visuais não são inocentes, mas sim construídas a partir de várias práticas, tecnologias, conhecimentos e intenções.

Este é um grande e atual desafio das ciências sociais, considerando que a fotografia no campo da cultura visual tem ganhado cada vez mais destaque como objeto e técnica de pesquisa qualitativa. De fato, as ciências sociais vêm incorporando aos seus domínios paradigmáticos novas bases teórico-epistemológicas, com novos temas, objetos e estratégias nesse campo científico. Neste arcabouço, dado o avanço das tecnologias da informação e dos suportes imagéticos, a fotografia destaca-se como instrumento do cientista social para entender os significados engendrados pelas imagens, suas formas de produção e mediação de sentidos.

Enfim, uma abordagem ampliada é necessária para a compreensão da fotografia como objeto e/ou técnica de pesquisa, consoante se procurou desenvolver neste trabalho, mediante exame do artigo de Warren (2008) e da tese de Andrade (2008), bem como pela discussão sobre as vantagens, limitações e as diretrizes de interpretação crítica, a rigor da expansiva utilização da fotografia em pesquisa qualitativa nas ciências sociais. 


\section{Referências}

ANDRADE, Mario Celso Ramiro de. O gabinê fluidificado e a fotografia dos espíritos no Brasil: a representação do invisível no território da arte em diálogo com a figuração de fantasmas, aparições luminosas e fenômenos paranormais. 2008. 162 f. Tese (Doutorado) - Escola de Comunicações e Artes, Universidade de São Paulo (USP), São Paulo, 2008.

COLLIER JUNIOR, John; COLLIER, Malcolm. Visual Anthropology: photography as a research method. Albuquerque: University of New Mexico Press, 1986.

DE PAULA, Silas; MARQUES, Kadma. A imagem Fotográfica como objeto da Sociologia da Arte. Revista de Ciências Sociais, v. 41, n.1, p. 17-26, 2010. Disponível em: <http://www.rcs.ufc.br/ edicoes/v41n1/rcs_v41n1a2.pdf $>$. Acesso em: 15 abr. 2016.

FERRAROTTI, Franco. Culture and Photography: Reading Sociology through a lens. International Journal of Politics, Culture and Society, v. 7, n. 1, p. 75- 95, 1993.

FLICK, Uwe. Introdução à pesquisa qualitativa. Tradução Joice Elias Costa. 3. ed. Porto Alegre: Artmed, 2009.

GODOY, Arilda Schmidt. Introdução à pesquisa qualitativa e suas qualidades. RAE, São Paulo, v. 35, n. 2, mar./abr., p. 57-63, 1995.

HARPER, Douglas. Reimagining visual methods: Galileo to Neuromancer. In: DENZIN, Norman K.; LINCOLN, Yvonna S. (Eds.). Handbook of qualitative research. 2. ed. Londres: Sage Publications Inc., 2000, p. 717-732.

LEITE, Míriam L. Moreira; FELDMAN-BIANO, Bela (Orgs.). 
Desafios da imagem. São Paulo: Papirus, 1998.

KOURY, Mauro Guilherme Pinheiro. A imagem nas ciências sociais no Brasil: um balanço crítico. BIB, Rio de Janeiro, n. 47, p. 49-63, $1^{\circ}$ semestre de 1999.

MARTINS, José de Souza. Sociologia da fotografia e da imagem. São Paulo: Contexto, 2008.

MEAD, Margaret. L'Anthropologie visuelle dans une discipline verbal. In: Pour une Anthropologie Visuelle. La Haye: Mouton Éditeur, 1979.

MEDINA FILHO, Antonio Luiz de. Importância das imagens na metodologia de pesquisa em psicologia social. Psicol. Soc., Belo Horizonte, v. 25, n. 2, p. 263-271, 2013. Disponível em: $<$ http://www.scielo.br/scielo.php?script=sci_arttext\&pid=S0102$71822013000200003 \& \operatorname{lng}=\mathrm{en} \& \mathrm{nrm}=\mathrm{iso}>$. Acesso em: 1 jun. 2016.

MELLO, Maria Teresa Villela Bandeira de. Os usos da imagem nas ciências sociais. Revista Estudos Históricos, n. 23, p. 214-219, 1999.

MENEZES, Mardônio. A fotografia como de produção de conhecimento nas ciências humanas e sociais: primeiras aproximações. Rev. Psicol. UNESP, Assis, v. 12, n. 1, p. 90102, jun. 2013. Disponível em <http://pepsic.bvsalud.org/scielo. php?script $=$ sci_arttext\&pid $=$ S1984-90442013000100009\&lng $=$ pt $\&$ nrm $=$ iso $>$. Acesso em: 1 jun. 2016.

MONTEIRO, Charles. História, fotografia e cidade: reflexões teórico-metodológicas sobre o campo de pesquisa. MÉTIS: história e cultura, v. 5, n. 9, p. 11-23, jan./jun. 2006. 
ROSE, Gillian. Visual Methodologies: an Introdution to the Interpretation of Visual Materials. Londres: Sage Publications Inc., 2001.

SANTOS, Patrícia Lessa dos. A imagem enquanto fonte de pesquisa: a fotografia publicitária. Iniciação científica Cesumar, Maringá, v. 2, n. 2, p. 63-68, ago./dez. 2000.

SOARES, Fernando Custódio; SUZUKI, Julio Cesar. Fotografia e história oral: imagem e memória na pesquisa com comunidades tradicionais. In: V Encontro de Grupos de Pesquisa "Agricultura, Desenvolvimento Regional e Transformações Socioespaciais". 2009. Disponível em:

$<$ http://w3.ufsm.br/gpet/engrup/vengrup/anais/7/Fernando $\% 20$ e\%20Julio\%20-\%20USP_2.pdf >. Acesso em: 2 maio 2015.

SONTAG, Susan. On Photography. New York: Rosetta Books, 1973.

SWEETMAN, Paul. Revealing habitus, illuminating practice: Bourdieu, photography and visual methods. Sociological Review, v. 57, n. 3, p. 491-511, 2009.

WARREN, Samantha. Empirical Challenges in Organizational Aesthetics Research: Towards a Sensual Methodology. Organization Studies, v. 29, n. 4, p. 559-580, abril 2008.

. Visual Methods in Organizational Research. In: BUCHANAN, David A.; BRYMAN, Alan (Eds.). The SAGE Handbook of Organizational Research Methods. Londres: Sage Publications Inc., 2009, p. 566-582. 